\title{
Age- and Sex-dependent Frequency of Fat Metaplasia and Other Structural Changes of the Sacroiliac Joints in Patients without Axial Spondyloarthritis: A Retrospective, Cross-sectional MRI Study
}

\author{
Katharina Ziegeler, Hamama Eshkal, Claudia Schorr, Joachim Sieper, Torsten Diekhoff, \\ Marcus R. Makowski, Bernd Hamm, and Kay-Geert A. Hermann
}

\begin{abstract}
Objective. To determine the prevalence of fat metaplasia and other structural lesions of the sacroiliac joints associated with axial spondyloarthritis in a nonrheumatological patient population.

Methods. Magnetic resonance imaging examinations that included the pelvis and were performed in patients without known rheumatological disease were used for this retrospective cross-sectional study. These images were evaluated for sacroiliac fat metaplasia, sclerosis, osteophytes, and joint space alterations such as erosions or ankylosis. Patients were divided into 7 age groups (15-24 to $\geq 75$ yrs). Prevalence of lesions across age groups was calculated. Possible clinical confounders (e.g., status post radiation, suspected inflammatory bowel disease) were investigated regarding their effect on lesion prevalence and extent, to exclude bias.

Results. A total of 485 patients were enrolled. Fat metaplasia was very common and increased with age, from a prevalence of $50.6 \%$ in the age groups $<45$, to $94.4 \%$ in patients $\geq 75$ years. Erosions were uncommon: $0.6 \%$ of patients $<45$, and $2.6 \%$ of the entire study population exhibited this feature, with no detectable age-dependent increase. Sclerosis and osteophytes were detected in $13.7 \%$ and $37.0 \%$ of patients, respectively. None of the investigated clinical confounders had a significant effect on lesion prevalence.

Conclusion. Our study shows a very high prevalence of fat metaplasia adjacent to the sacroiliac joint in asymptomatic patients, while erosions are extremely uncommon. (First Release April 15 2018; J Rheumatol 2018;45:915-21; doi:10.3899/jrheum.170904)
\end{abstract}

Key Indexing Terms:

MAGNETIC RESONANCE IMAGING

SACROILIITIS EPIDEMIOLOGY
ANKYLOSING SPONDYLITIS
AXIAL SPONDYLOARTHRITIS
Axial spondyloarthritis (axSpA) is a term that describes a group of diseases with a predominant inflammation of the axial skeleton. It may be associated with other clinical conditions, such as enthesitis, peripheral oligoarthritis, or uveitis, and often first manifests in the sacroiliac joints (SIJ) ${ }^{1}$. While radiography still remains the first-line imaging modality for

From the Department of Radiology, and the Department of Rheumatology and Gastroenterology, Charité - Universitätsmedizin Berlin, Berlin, Germany.

K. Ziegeler, MD, Department of Radiology, Charité Berlin; H. Eshkal, $M D$, Department of Radiology, Charité Berlin; C. Schorr, Department of Radiology, Charité Berlin; J. Sieper, MD, PhD, Department of

Rheumatology and Gastroenterology, Charité Berlin; T. Diekhoff, $M D$

Department of Radiology, Charité Berlin; M.R. Makowski, MD, PhD,

Department of Radiology, Charité Berlin; B. Hamm, MD, PhD,

Professor of Radiology, Charité Berlin; K.G. Hermann, MD, PhD,

Department of Radiology, Charité Berlin.

Address correspondence to Dr. K.G. Hermann, Charité - Universitätsmedizin Berlin, Department of Radiology (CCM), Charitéplatz 1, 10117 Berlin, Germany.E-mail:kghermann@gmail.com

Accepted for publication December 14, 2017. the diagnosis and classification of axSpA, the value of magnetic resonance imaging (MRI) in the detection of both acute and chronic changes of SIJ during the course of axSpA has been discussed by a task force of the European League Against Rheumatism ${ }^{2}$ and by the Assessment of SpondyloArthritis international Society ${ }^{3}$.

One of the chronic lesions described as typical for sacroiliitis is fat metaplasia ${ }^{4,5}$, which manifests as increased periarticular signal intensity on T1-weighted MR images. Fat metaplasia is assumed to be an intermediate stage between active inflammation and formation of new bone, as in ankylosis ${ }^{4}$. However, MR signal characteristics of bone in general are dependent on the relative proportions of trabecular bone, fat, and water ${ }^{6}$. While the proportion of hematopoietic bone marrow decreases gradually with age, the proportion of fat marrow (yellow marrow) increases over time ${ }^{6}$. Pathological conditions associated with increases in adipose tissue in bone marrow also include aplastic anemia ${ }^{7}$, osteoporosis and osteopenia ${ }^{8}$, radiation ${ }^{9}$,

Personal non-commercial use only. The Journal of Rheumatology Copyright $\subset$ 2018. All rights reserved. 
and treatment with certain immunosuppressive agents such as azathioprine ${ }^{10}$.

Other structural bone changes observed in patients with axSpA include subchondral sclerosis, erosions, bony bridges, and ankylosis ${ }^{11}$. These changes, however, may also occur in other conditions such as degenerative joint disease ${ }^{12}$. Further, if these structural changes, as well as alterations in periarticular fat content, are detected by MRI, they are to date not considered definitive of axSpA in the absence of active inflammatory lesions such as bone marrow edema ${ }^{11}$.

Analysis of structural SIJ damage, still preferentially by conventional radiographs ${ }^{2}$, is well established for the diagnosis of axSpA and for assessing progression and the response to treatment regimens in the setting of clinical trials. We have recently reported that T1-weighted MRI sequences are superior to conventional radiographs in the detection of erosions of SIJ using low-dose computed tomography (CT) as reference ${ }^{13}$. Studies have investigated the frequency of structural lesions in patients with postpartum lower back pain $^{14}$ and asymptomatic hyperparathyroidism ${ }^{15}$. However, reference data for the occurrence of such structural SIJ lesions on T1-weighted MR images obtained in the normal population are available only for control groups in papers reporting the distribution of findings of axSpA and therefore are either healthy volunteers or patients with nonspecific back pain $16,17,18,19$.

Our study set out to analyze the prevalence of fat metaplasia, erosions, sclerosis, and alterations of joint width using MRI across age groups in a patient population without known rheumatological disease.

\section{MATERIALS AND METHODS}

Our retrospective study included all patients who underwent an MRI examination of the pelvic region at the Department of Radiology of the Charité - Universitätsmedizin Berlin during a 3-year period. Examinations dedicated to the detection of SIJ pathology were not included. A range of possible influencing factors on bone marrow conversion was recorded from the electronic patient records: status post-irradiation of the spine or lower abdomen, immunosuppressive therapy including chemotherapy, hematological disease (especially aplastic anemia), and osteoporosis.

All patients gave written informed consent to anonymized use of their data prior to image acquisition, as part of the routine clinical protocol at our department. The local ethics committee waived approval because of the retrospective nature of our study.

Axial T1-weighted sequences were used for this analysis. Depending on the protocol and body region imaged, these were either conventional spin echo or gradient echo sequences with a slice thickness of $4 \mathrm{~mm}$ and $5 \mathrm{~mm}$, respectively. All images were acquired on 1.5 Tesla MRI scanners (SOMATOM Avanto or SOMATOM Symphony, Siemens Healthcare).

A standardized scoring system was defined for the purpose of this evaluation. All items except fat metaplasia (sclerosis, osteophytes, and joint space alterations, including erosions) were evaluated for each joint individually (2 joints per patient). Fat metaplasia was evaluated for the sacrum and ilium separately ( 4 regions per patient) to identify differences between these bones. A quadrant-based scoring approach as used in most other dedicated scoring systems or axSpA could not be used because only axial images were evaluated.

Expanding on previous definitions ${ }^{11,20}$, fat metaplasia in our study was not only defined as adjacent to the joint, but also graded semiquantitatively regarding its extent (Figure 1), further developing scoring methods described earlier by our group ${ }^{21}$. The border of these lesions to the nonarticular side was not clearly defined because of the varying slice thickness of the MRI sequences used. Joint space alterations were scored categorically, and a distinction was made between joint space irregularities (partially irregular joint surface, with preserved continuity of T1 hypointense cortical bone) and definite erosion (definite discontinuity of cortical bone). Both sclerosis and osteophytes were again graded semiquantitatively by measuring their extent and then assigning scoring values. An overview of the resulting score definitions is given in Table 1. Further, an atlas (Figure 1, and Supplementary Figures $1-3$, available with the online version of this article) was compiled to aid standardized image interpretation during reading sessions.

All images were systematically evaluated by a radiologist in training (HE, 3 yrs of experience in musculoskeletal radiology), who was blinded to all patient data. Prior to image evaluation, a training session with an expert radiologist (KGH, 15 years of experience in musculoskeletal radiology) was carried out on 20 test datasets, which were not part of the main analysis. To calculate interrater reliability as a measure of internal consistency of the scoring system applied, the expert radiologist $(\mathrm{KGH})$ also scored a random sample of $10 \%$ of the study population.

Statistical analyses were carried out using IBM SPSS Version 22 (IBM Corp.). Descriptive analysis included calculation of percentages of patient characteristics. Patterns of fat metaplasia (sacrum and ilium individually) were compiled for men and women, and each age group, separately.

A sum score of all individual scorings of fatty lesions per patient was calculated (4 regions per patient, sum score range $0-20$ ). Pearson correlation coefficients (Pearson r) were calculated to detect correlations between age and extent of fat metaplasia. Patients with a sum score of 3 or higher were considered overall positive for fat metaplasia, to avoid bias resulting from subtle lesions. Patients with definite erosion (score 2 in the category joint space) on 1 or both sides were considered positive for erosion. Patients with a score of $\geq 1$ for sclerosis or osteophytes on either side in the corresponding category were considered positive for the respective characteristic. To test for significance of any age-related trends, the Jonckheere-Terpstra test was applied.

Subgroups chosen for further analysis were the predefined clinical confounders retrieved from patient records (irradiation, immunosuppression, hematological disease, and osteoporosis) as well as suspected inflammatory bowel disease (IBD; in this setting, this was defined as all patients who received a dedicated small intestine examination such as MRI Sellink). $\mathrm{T}$ tests for unpaired samples were used to detect differences in mean sum scores between subgroups. Kendall tau c was used to detect associations between degrees of fat metaplasia and clinical data (radiotherapy, immunosuppression, osteoporosis). Intraclass correlation coefficients (ICC) were calculated to test for interrater reliability of the scoring system using a 2-way mixed model $[\operatorname{ICC}(3,2)]^{22}$. A significance level of $p<0.05$ was assumed for all tests.

\section{RESULTS}

Patient population. A total of 485 patients were identified for enrollment in this retrospective analysis. Patients with missing or incomplete clinical data were excluded from further analysis $(\mathrm{n}=31)$, resulting in a patient pool of $\mathrm{n}=454$. MRI datasets analyzed included MRI of the abdomen and pelvis $(n=309,68 \%)$, MRI of the small intestine/ MRI Sellink $(\mathrm{n}=125,27.5 \%)$, hips $(\mathrm{n}=17,3.7 \%)$, and rectum, prostate, and kidneys $(\mathrm{n}=1$ each, $0.2 \%)$. Patient characteristics including clinical data are summarized in Table 2.

Fat metaplasia across age groups. Fat metaplasia was very common and was observed in $50.6 \%$ of patients $<45$ years 

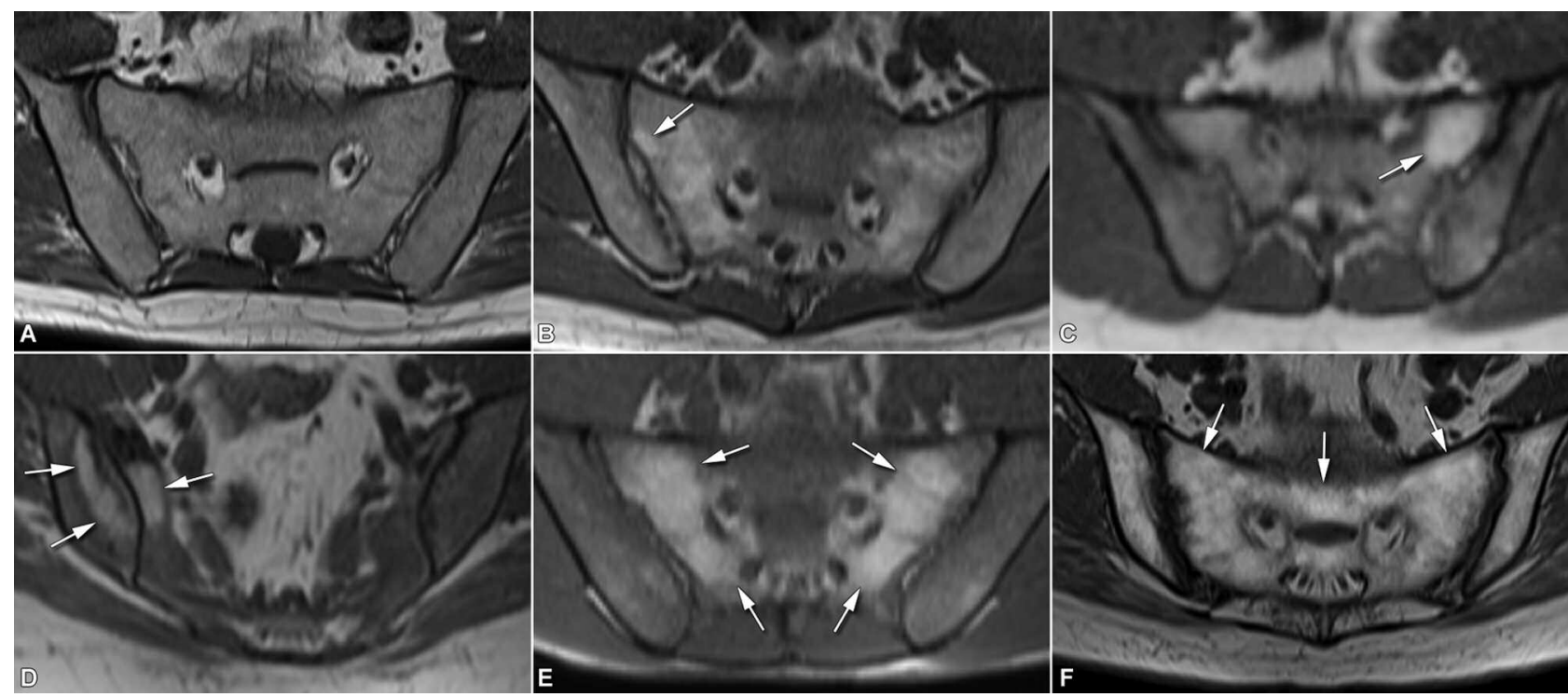

Figure 1. Atlas section on fat deposition. T1-weighted axial MR images from the patient population. A. Normal bone marrow signal $(\mathrm{score}=0)$. B. Focal fat metaplasia (score = 1). C. Patchy fat metaplasia $($ score $=2)$. D. Band-like fat metaplasia $($ score $=3)$. E. Extensive subtotal fat metaplasia (e.g., excluding interforaminal region of sacrum; score $=4)$. F. Extensive fat metaplasia (score $=5$ ). MR: magnetic resonance.

Table 1. Standardized score for image evaluation.

\begin{tabular}{lcccc}
\hline Score & Fat Metaplasia & Joint Space & Sclerosis & Osteophytes \\
\hline 0 & Normal & Normal & Cortical bone depth $\leq 5 \mathrm{~mm}$ & None \\
1 & Focal $(\max 1 \mathrm{~cm})$ & $\begin{array}{c}\text { Irregular/possibly } \\
\text { erosive* }\end{array}$ & $\begin{array}{c}\text { Cortical bone depth } \\
5-10 \mathrm{~mm}\end{array}$ & $\leq 5 \mathrm{~mm}$ \\
2 & Patchy $(1-2.5 \mathrm{~cm})$ & Definitely erosive** & Cortical bone depth \\
$>10 \mathrm{~mm}$ & $>5 \mathrm{~mm}$ \\
3 & Band-like & Ankylosis & & Bridging \\
4 & $\begin{array}{c}\text { Extensive (subtotal, e.g., } \\
\text { excluding interforaminal } \\
\text { region of sacrum) }\end{array}$ & & & \\
& Extensive (total) & & & \\
\hline
\end{tabular}

* Irregular joint surface with preserved continuity of hypointense cortical bone. ** Discontinuity of hypointense cortical bone. For image examples, refer to Figure 1, and Supplementary Figures, available with the online version of this article.

Table 2. Characteristics of the patient population as divided by age group. Clinical confounders were derived from electronic patient records. Values are n (\%) unless otherwise specified.

\begin{tabular}{|c|c|c|c|c|c|c|c|}
\hline \multirow{2}{*}{$\begin{array}{l}\text { Age, } \\
\text { yrs }\end{array}$} & \multirow{2}{*}{$\begin{array}{c}\text { Patients, } \\
\mathrm{n}\end{array}$} & \multicolumn{2}{|c|}{ Sex } & \multicolumn{4}{|c|}{ Confounders } \\
\hline & & Female & Male & Radiation* & Immunosuppression $^{\dagger}$ & $\begin{array}{l}\text { Hematological } \\
\text { Disease }\end{array}$ & Osteoporosis \\
\hline $15-24$ & 38 & $21(55)$ & $17(45)$ & $0(0)$ & $17(45)$ & $0(0)$ & $0(0)$ \\
\hline $25-34$ & 50 & $33(66)$ & $17(43)$ & $1(2)$ & $23(46)$ & $0(0)$ & $0(0)$ \\
\hline $35-44$ & 74 & $28(38)$ & $46(62)$ & $2(3)$ & $38(51)$ & $0(0)$ & $2(3)$ \\
\hline $45-54$ & 75 & $39(52)$ & $36(48)$ & $10(13)$ & $46(61)$ & $0(0)$ & $6(8)$ \\
\hline $55-64$ & 64 & $34(53)$ & $30(47)$ & $13(20)$ & $34(53)$ & $1(2)$ & $0(0)$ \\
\hline $65-74$ & 99 & $43(43)$ & $56(57)$ & $13(13)$ & $40(40)$ & $1(1)$ & $7(7)$ \\
\hline$\geq 75$ & 54 & $23(43)$ & $31(57)$ & $9(17)$ & $24(44)$ & $0(0)$ & $6(11)$ \\
\hline All & 454 & $221(49)$ & $233(51)$ & $48(11)$ & $222(49)$ & $2(<1)$ & $21(5)$ \\
\hline
\end{tabular}

* Radiation of lower spine or pelvic region. ${ }^{\dagger}$ Administration of any immunosuppressive agent, including chemotherapy. 
Table 3. Patterns of fat metaplasia according to age groups (years). Values are $\mathrm{n}(\%)$ unless otherwise stated.

\begin{tabular}{|c|c|c|c|c|c|c|c|c|c|c|c|c|c|c|}
\hline Score & $\begin{array}{l}15-24 \\
\mathrm{n}=33\end{array}$ & $\begin{array}{r}25-34, \\
\mathrm{n}=33\end{array}$ & $\begin{array}{l}35-44 \\
\mathrm{n}=28\end{array}$ & $\begin{array}{c}\text { Women } \\
45-54, \\
\mathrm{n}=39\end{array}$ & $\begin{array}{l}55-64 \\
\mathrm{n}=34\end{array}$ & $\begin{array}{l}65-74 \\
\mathrm{n}=43\end{array}$ & $\begin{array}{c}\geq 75 \\
\mathrm{n}=23\end{array}$ & $\begin{array}{l}15-24, \\
\mathrm{n}=17\end{array}$ & $\begin{array}{l}25-34 \\
\mathrm{n}=17\end{array}$ & $\begin{array}{l}35-44 \\
\mathrm{n}=46\end{array}$ & $\begin{array}{c}\text { Men } \\
45-54, \\
n=36\end{array}$ & $\begin{array}{c}55-64 \\
\mathrm{n}=30\end{array}$ & $\begin{array}{l}65-74 \\
\mathrm{n}=56\end{array}$ & $\begin{array}{c}\geq 75, \\
\mathrm{n}=31\end{array}$ \\
\hline & \multicolumn{14}{|c|}{ Frequency of Scores } \\
\hline 0 & $18(86)$ & $23(70)$ & $14(50)$ & $12(31)$ & $8(24)$ & $5(12)$ & $2(9)$ & $16(94)$ & $9(53)$ & $15(33)$ & $17(47)$ & $13(43)$ & $8(14)$ & $1(3)$ \\
\hline 1 & $1(5)$ & $5(15)$ & $11(39)$ & $17(44)$ & $16(47)$ & $8(19)$ & $5(22)$ & $1(6)$ & $5(29)$ & $22(48)$ & $10(28)$ & $10(33)$ & $20(36)$ & $10(32)$ \\
\hline 2 & $2(10)$ & $4(12)$ & $1(4)$ & $6(15)$ & $5(15)$ & $15(35)$ & $6(26$ & 0 & $3(18)$ & $4(9)$ & $4(11)$ & $3(10)$ & $17(30)$ & $12(39)$ \\
\hline 5 & 0 & 0 & 0 & 0 & 0 & $9(21)$ & $4(17)$ & 0 & 0 & 0 & 0 & 0 & $2(4)$ & $3(10)$ \\
\hline \multicolumn{15}{|c|}{ Sacrum } \\
\hline 0 & $14(67)$ & $16(48)$ & $10(36)$ & $6(15)$ & $4(12)$ & $4(9)$ & $2(9)$ & $16(94)$ & $4(24)$ & $7(15)$ & $11(31)$ & $7(23)$ & $4(7)$ & $1(3)$ \\
\hline 1 & $2(10)$ & $6(18)$ & $8(29)$ & $11(28)$ & $9(26)$ & $3(7)$ & $1(4)$ & $1(6)$ & $4(24)$ & $10(22)$ & $5(14)$ & $7(23)$ & $9(16)$ & $1(3)$ \\
\hline 2 & $2(10)$ & $10(30)$ & $7(25)$ & $14(36)$ & $13(38)$ & $9(21)$ & $3(13)$ & 0 & $9(53)$ & $15(33)$ & $12(33)$ & $9(30)$ & $12(21)$ & $7(23)$ \\
\hline 3 & 0 & 0 & 0 & $1(3)$ & 0 & 0 & 0 & 0 & 0 & 0 & 0 & $1(3)$ & 0 & 0 \\
\hline & $4(19)$ & $14(42)$ & $16(57)$ & $30(77)$ & 27 (79) & $38(88)$ & $21(91)$ & $1(6)$ & $11(65)$ & $36(78)$ & $23(64)$ & $20(67)$ & $51(91)$ & $30(97)$ \\
\hline
\end{tabular}

For definitions of scores, see Table 1. Percentages rounded to whole numbers. Resulting overall prevalence of fat metaplasia in patients $<45: \mathrm{n}=82 / 162$ $(50.6 \%)$; in patients $\geq 75: \mathrm{n}=51 / 54(94.4 \%)$.

and $94.4 \%$ of patients $\geq 75$ years. Table 3 shows detailed distribution of patterns of fat metaplasia across all age groups, for male and female patients. Focal (score of 1) and patchy (score of 2) deposition patterns were the predominant findings in patients $\leq 45$ years, while more confluent (score of 4) and extensive (score of 5) patterns increased in older age groups. Not only the prevalence but also the extent of fat metaplasia increased with age. The mean $( \pm$ SD) sum scores of fat metaplasia increased from $0.89( \pm 2.08)$ in patients $\leq 24$ years to $11.56( \pm 5.29)$ in patients $\geq 75$ years. The correlation between age and extent of fat metaplasia was moderate, with a Pearson $r$ of $0.550(p<0.001)$. The Jonckheere-Terpstra test showed that fat metaplasia was not distributed equally across age groups, independent of sex $(\mathrm{p}<0.001)$, thereby confirming the age-dependent increase seen in Table 3.
Structural lesions. Structural lesions (i.e., sclerosis, erosions, and osteophytes) were observed at markedly lower frequencies than fat metaplasia. No case of ankylosis was observed in our study population. Table 4 presents the prevalence of structural lesions (excluding fat metaplasia) across age groups. In the age groups $<45$ years, $10 \%, 0.6 \%$, and $20 \%$ of patients had sclerosis, erosions, and osteophytes, respectively. Overall, osteophytes were significantly less prevalent in the female patient population $(24.9 \%$ vs $48.5 \%$, $\mathrm{p}<0.001$ ). Sex-specific prevalence for sclerosis (females: $16.3 \%$, males: $11.2 \%$; $=0.133$ ) or erosions (females: $4.1 \%$, males: $1.3 \% ; \mathrm{p}=0.081$ ) may indicate a weak predilection for female patients, although neither trend was statistically significant.

Radiotherapy. Overall, 48 patients had undergone radio-

Table 4. Structural lesions across age groups. Values are n (\%) unless otherwise specified.

\begin{tabular}{lcccc}
\hline Age, yrs & No. Patients & Sclerosis* & Erosion $^{\dagger}$ & Osteophytes $^{\diamond}$ \\
\hline $15-24$ & 38 & $1(3)$ & $1(3)$ & $0(0)$ \\
$25-34$ & 50 & $6(12)$ & $0(0)$ & $7(14)$ \\
$35-44$ & 74 & $9(12)$ & $0(0)$ & $26(35)$ \\
$45-54$ & 75 & $9(12)$ & $5(7)$ & $21(28)$ \\
$55-64$ & 64 & $5(8)$ & $1(2)$ & $29(45)$ \\
$65-74$ & 99 & $22(22)$ & $3(3)$ & $54(55)$ \\
$\geq 75$ & 54 & $10(19)$ & $2(4)$ & $31(57)$ \\
All & 454 & $62(14)$ & $12(3)$ & $168(37)$ \\
\hline
\end{tabular}

Percentages rounded to whole numbers. $*$ Score $\geq 1$ for sclerosis on either side. ${ }^{\dagger}$ Score $=2$ for joint space on either side. ${ }^{\diamond}$ Score $\geq 1$ for osteophytes on either side. See Table 1 for score definitions. Resulting prevalence in the age group $<45$ years: sclerosis $(n=16,10.0 \%)$, erosion $(n=1,0.6 \%)$, and osteophytes $(n=32,20.0 \%)$. 
therapy. Mean $( \pm$ SD) sum scores for fat metaplasia were $10.30( \pm 5.60)$ and $6.12( \pm 5.52)$ for patients with a history of radiotherapy versus those without; the difference was highly significant $(\mathrm{p}<0.001)$. However, Kendall tau $\mathrm{c}$ for the association of radiotherapy and fat metaplasia was very low at $0.157(\mathrm{p}<0.001)$. Patients with a history of radiotherapy had a significantly higher mean age (62.33 vs 51.72 yrs, $\mathrm{p}<0.001)$ than those without.

Immunosupression and hematological disease. Immunosuppressive agents were part of the medication of 222 patients of our study population. Mean $( \pm$ SD) fat metaplasia sum scores for patients with and without immunosuppression did not differ significantly at $6.63( \pm 5.58)$ and $6.50( \pm 5.77)$, respectively. Immunosuppression and fat metaplasia were not associated significantly (Kendall tau c: $0.02, \mathrm{p}=0.703$ ). Patients with immunosuppression were on average 51.95 years old, while patients without were on average 53.70 years; the difference was not statistically significant. Because only 2 patients had a hematological disease in our study population, its effect on fat metaplasia was not investigated further.

Osteoporosis. Patients diagnosed with osteoporosis $(\mathrm{n}=31)$ had a significantly lower mean $( \pm \mathrm{SD})$ sum score of fat metaplasia with $6.34( \pm 5.59)$ compared to $11.29( \pm 5.41)$ in patients without osteoporosis. The degree of association between osteoporosis and fat metaplasia was extremely low at a Kendall tau c of $0.09(\mathrm{p}<0.001)$. Patients with osteoporosis were on average 52.28 years old, while patients without were on average 64.43 years; the difference was statistically significant $(\mathrm{p}<0.001)$.

Suspected IBD. The study population included patients who underwent MRI for the detection of IBD (e.g., MRI Sellink and MRI of the small intestine). In this subset $(n=125)$, the frequency of sclerosis (14\% in both Sellink group and all other patients) and erosions (4\% in Sellink group vs $2 \%$ in all other patients) did not differ from all other patients. Fat metaplasia was less prevalent in the Sellink group $(61 \%$ vs $75 \%, \mathrm{p}=0.005)$ and also less extensive, as expressed by mean sum scores of 4.69 versus $7.28(\mathrm{p}<0.001)$.

Interrater reliability. ICC were computed to test for interrater reliability. ICC were 0.964 (95\% CI $0.952-0.972)$ for fat metaplasia, 0.812 (95\% CI 0.722-0.872) for joint space alterations, 0.826 (95\% CI 0.744-0.882) for sclerosis, and 0.838 (95\% CI 0.762-0.891) for osteophytes. All calculated coefficients were statistically significant $(\mathrm{p}<0.001)$. Overall, ICC averaged at 0.860 , indicating good interrater reliability ${ }^{22}$.

\section{DISCUSSION}

The aim of our analysis was to define the occurrence of changes typically associated with axSpA such as sclerosis, erosions, and fat metaplasia in periarticular bone marrow in the SIJ of a population without known axSpA. The results of our study show that periarticular fat metaplasia at the SIJ is a common finding and can be detected in up to $59.4 \%$ of patients $\leq 45$ years without rheumatological disease. Additionally, our data demonstrate a significant age-dependent, sex-independent increase in the extent of these lesions. On the other hand, erosions are nearly absent in the age groups $\leq 45$ years and are also an infrequent finding in age groups $>45$ years, indicating that erosions are indeed rather specific for axSpA $\mathrm{A}^{3,23,24}$.

Our observations underline the importance of precisely defining fat metaplasia as a structural lesion in axSpA-associated sacroiliitis. Fatty lesions, or fat metaplasia, have been described as part of the spectrum of axSpA since the $1990 \mathrm{~s}^{11,25,26,27,28}$. Changes in the fat content of periarticular bone marrow are also used to evaluate the response to treatment $t^{5,29}$. Some data exist about the prevalence of structural lesions in healthy volunteers or patients with nonspecific back pain ${ }^{16,17,18,19}$; however, these control groups were not analyzed for fat metaplasia pattern or age distribution. Interestingly, analysis of patterns of fat metaplasia suggests an age-dependent transition from patchy lesions to more confluent ones. Further studies on healthy individuals may deepen our insights into the pathohistological mechanisms underlying this observation in the future.

Erosions are the hallmark of all forms of arthritis, and erosions are usually interpreted to suggest definite sacroiliitis in a clinical context. In our analysis, we concentrated on definite rather than probable erosions (e.g., slight joint contour irregularities). In the population investigated here, definite erosions were detected at a rather low frequency of $0.6 \%$ in the age groups $<45$ years. The frequency of erosions did not dramatically increase with age and remained at a low $3 \%$ for the whole study population.

Sclerosis and osteophytes occurred in $10.0 \%$ and $20.0 \%$, respectively, in patients $<45$ years of age. However, prevalence increased with age and eventually reached $18.5 \%$ and $57.4 \%$, respectively, in the age group $\geq 75$ years. These frequencies are slightly lower than those reported by Eno, et $a l$, who found degenerative changes in $65.1 \%$ of SIJ CT of asymptomatic patients ${ }^{30}$, which is best explained by the superior capacity of $\mathrm{CT}$ to detect osseous changes ${ }^{13}$. Additionally, the MRI protocols used in our study patients were not primarily intended for SIJ imaging; therefore, the slice thickness was 4 or $5 \mathrm{~mm}$, and we analyzed axial images rather than the recommended oblique coronal planes ${ }^{2}$. As a result, more subtle changes may have gone undetected. This holds true especially for erosions, which are challenging to detect even in dedicated SIJ sequences.

Because we did not investigate a healthy population, possible clinical confounders in terms of fat metaplasia were taken into account in our analysis. It is well-established that radiation depletes hematopoietic red marrow, resulting in a higher fat content of irradiated areas ${ }^{9}$. In our analysis, patients with a history of radiotherapy had a significantly larger extent of fat metaplasia. We therefore conclude that because of inclusion of patients in post-irradiation status, our data may

Personal non-commercial use only. The Journal of Rheumatology Copyright (C) 2018. All rights reserved. 
slightly overestimate the prevalence of fat metaplasia. Almost half of our patient population was taking immunosuppressive therapy. However, we found no significant association between immunosuppressive therapy and fat metaplasia identified by MRI. Because detailed data on amount and duration of treatment were not available in this retrospective setting, we cannot draw any conclusions regarding direct influences. Our findings regarding fat metaplasia in patients with osteoporosis appear unexpected: not only was fat metaplasia significantly less extensive in them, but the mean age of patients with osteoporosis was also significantly lower than that of patients without. A possible explanation is underreporting of osteoporosis in our electronic patient records, a known phenomenon in epidemiological studies ${ }^{31}$. In the general German population, the estimated prevalence of osteoporosis in individuals $>65$ years of age is $12.1 \%{ }^{32}$, while it was $8.5 \%$ in the respective part of our study population.

Another important confounder in our study is the substantial proportion of patients with proven or suspected IBD: $>25 \%$ of examinations were dedicated IBD examinations. The links between IBD and sacroiliitis have long been established ${ }^{33}$, and asymptomatic radiographic sacroiliitis in patients with IBD patients has a reported prevalence of $4-18 \%{ }^{34,35}$. In our study population, however, these patients did not have more erosions or sclerosis, nor did they have significantly fewer osteophytes and less extensive fat metaplasia than the study population as a whole. We therefore assume that the inclusion of these patients did not lead to an overestimation of axSpA-associated changes.

MRI datasets were not specifically acquired to image SIJ and consequently, our scoring system was designed to evaluate the entire bones and not only the periarticular regions of the ilium and sacrum. However, to strongly attribute fat metaplasia to axSpA, a close proximity to the joint contour was mandatory ${ }^{3}$. Yet the scores of 1 (focal) and 2 (patchy) as defined in our scoring system are defined by the pattern within the bone, and a close relation to the cortical bone was not required. This limitation needs to be taken into account. Further, methodological limitations include the retrospective nature of our study design with some inherent selection bias. Also, further clinical confounders such as impaired mobility, multiparity, increased axial load, and altered spinal mechanics after spinal surgery were not investigated. As the presence of rheumatological disease could only be extracted from patient records, individuals with undiagnosed subclinical forms of the disease may have inadvertently been included. Future research should establish the prevalence of lesions in a healthy population, preferably excluding all clinical confounders by using a prospective study design.

Our study shows a very high prevalence of periarticular fat metaplasia adjacent to the SIJ in asymptomatic patients; this prevalence increases with age, while erosions are uncommon. Further research should be done to better define fat metaplasia in the context of axSpA, to avoid misinterpretation.
ACKNOWLEDGMENT

We thank Bettina Herwig for language editing.

\section{ONLINE SUPPLEMENT}

Supplementary material accompanies the online version of this article.

\section{REFERENCES}

1. Rudwaleit M, van der Heijde D, Landewe R, Listing J, Akkoc N, Brandt J, et al. The development of Assessment of SpondyloArthritis international Society classification criteria for axial spondyloarthritis (part II): validation and final selection. Ann Rheum Dis 2009;68:777-83.

2. Mandl P, Navarro-Compan V, Terslev L, Aegerter P, van der Heijde D, D'Agostino MA, et al; European League Against Rheumatism (EULAR). EULAR recommendations for the use of imaging in the diagnosis and management of spondyloarthritis in clinical practice. Ann Rheum Dis 2015;74:1327-39.

3. Lambert RG, Bakker PA, van der Heijde D, Weber U, Rudwaleit M, Hermann KG, et al. Defining active sacroiliitis on MRI for classification of axial spondyloarthritis: update by the ASAS MRI working group. Ann Rheum Dis 2016;75:1958-63 .

4. Maksymowych WP, Wichuk S, Chiowchanwisawakit P, Lambert RG, Pedersen SJ. Fat metaplasia and backfill are key intermediaries in the development of sacroiliac joint ankylosis in patients with ankylosing spondylitis. Arthritis Rheumatol 2014;66:2958-67.

5. Song IH, Hermann KG, Haibel H, Althoff CE, Poddubnyy D, Listing $\mathrm{J}$, et al. Relationship between active inflammatory lesions in the spine and sacroiliac joints and new development of chronic lesions on whole-body MRI in early axial spondyloarthritis: results of the ESTHER trial at week 48. Ann Rheum Dis 2011;70:1257-63.

6. Moulopoulos LA, Dimopoulos MA. Magnetic resonance imaging of the bone marrow in hematologic malignancies. Blood 1997;90:2127-47.

7. Kaplan PA, Asleson RJ, Klassen LW, Duggan MJ. Bone marrow patterns in aplastic anemia: observations with 1.5-T MR imaging. Radiology 1987;164:441-4.

8. Yeung DK, Griffith JF, Antonio GE, Lee FK, Woo J, Leung PC. Osteoporosis is associated with increased marrow fat content and decreased marrow fat unsaturation: a proton MR spectroscopy study. J Magn Reson Imaging 2005;22:279-85.

9. Carmona R, Pritz J, Bydder M, Gulaya S, Zhu H, Williamson CW, et al. Fat composition changes in bone marrow during chemotherapy and radiation therapy. Int J Radiat Oncol Biol Phys 2014;90:155-63.

10. Hadda V, Pandey BD, Gupta R, Goel A. Azathioprine induced pancytopenia: a serious complication. J Postgrad Med 2009; 55:139-40.

11. Rudwaleit M, Jurik AG, Hermann KG, Landewe R, van der Heijde $\mathrm{D}$, Baraliakos X, et al. Defining active sacroiliitis on magnetic resonance imaging (MRI) for classification of axial spondyloarthritis: a consensual approach by the ASAS/OMERACT MRI group. Ann Rheum Dis 2009;68:1520-7.

12. Resnick D, Niwayama G, Goergen TG. Comparison of radiographic abnormalities of the sacroiliac joint in degenerative disease and ankylosing spondylitis. AJR Am J Roentgenol 1977;128:189-96.

13. Diekhoff T, Hermann KA, Greese J, Schwenke C, Poddubnyy D, Hamm B, et al. Comparison of MRI with radiography for detecting structural lesions of the sacroiliac joint using CT as standard of reference: results from the SIMACT study. Ann Rheum Dis 2017;76:1502-8

14. Eshed I, Miloh-Raz H, Dulitzki M, Lidar Z, Aharoni D, Liberman $\mathrm{B}$, et al. Peripartum changes of the sacroiliac joints on MRI: increasing mechanical load correlating with signs of edema and inflammation kindling spondyloarthropathy in the genetically prone. Clin Rheumatol 2015;34:1419-26.

Personal non-commercial use only. The Journal of Rheumatology Copyright $\odot$ (2018. All rights reserved 
15. Tezcan ME, Temizkan S, Ozal ST, Gul D, Aydin K, Ozderya A, et al. Evaluation of acute and chronic MRI features of sacroiliitis in asymptomatic primary hyperparathyroid patients. Clin Rheumatol 2016;35:2777-82

16. Weber U, Zubler V, Pedersen SJ, Rufibach K, Lambert RG, Chan $\mathrm{SM}$, et al. Development and validation of a magnetic resonance imaging reference criterion for defining a positive sacroiliac joint magnetic resonance imaging finding in spondyloarthritis. Arthritis Care Res 2013;65:977-85.

17. Weber U, Lambert RG, Ostergaard M, Hodler J, Pedersen SJ, Maksymowych WP. The diagnostic utility of magnetic resonance imaging in spondylarthritis: an international multicenter evaluation of one hundred eighty-seven subjects. Arthritis Rheum 2010;62:3048-58.

18. Weber U, Lambert RG, Pedersen SJ, Hodler J, Ostergaard M, Maksymowych WP. Assessment of structural lesions in sacroiliac joints enhances diagnostic utility of magnetic resonance imaging in early spondylarthritis. Arthritis Care Res 2010;62:1763-71.

19. Oliveira TL, Maksymowych WP, Lambert RGW, Muccioli C, Fernandes ARC, Pinheiro MM. Sacroiliac joint magnetic resonance imaging in asymptomatic patients with recurrent acute anterior uveitis: a proof-of-concept study. J Rheumatol 2017 ;44:1833-40.

20. Weber U, Pedersen SJ, Zubler V, Rufibach K, Chan SM, Lambert $\mathrm{RG}$, et al. Fat infiltration on magnetic resonance imaging of the sacroiliac joints has limited diagnostic utility in nonradiographic axial spondyloarthritis. J Rheumatol 2014;41:75-83.

21. Krohn M, Braum LS, Sieper J, Song IH, Weiss A, Callhoff J, et al. Erosions and fatty lesions of sacroiliac joints in patients with axial spondyloarthritis: evaluation of different MRI techniques and two scoring methods. J Rheumatol 2014;41:473-80.

22. Koo TK, Li MY. A guideline of selecting and reporting intraclass correlation coefficients for reliability research. J Chiropr Med 2016;15:155-63.

23. Weber U, Ostergaard M, Lambert RG, Pedersen SJ, Chan SM, Zubler V, et al. Candidate lesion-based criteria for defining a positive sacroiliac joint MRI in two cohorts of patients with axial spondyloarthritis. Ann Rheum Dis 2015;74:1976-82.

24. Bakker PA, Ez-Zaitouni Z, van Lunteren M, van den Berg R, De Hooge M, Fagerli KM, et al. Are additional tests needed to rule out axial spondyloarthritis in patients ages 16-45 years with short-duration chronic back pain and maximally one spondyloarthritis feature? Arthritis Care Res 2016;68:1726-30.
25. Bollow M, Braun J, Hamm B, Eggens U, Schilling A, Konig H, et al. Early sacroiliitis in patients with spondyloarthropathy: evaluation with dynamic gadolinium-enhanced MR imaging. Radiology 1995;194:529-36

26. Brandt HC, Spiller I, Song IH, Vahldiek JL, Rudwaleit M, Sieper J. Performance of referral recommendations in patients with chronic back pain and suspected axial spondyloarthritis. Ann Rheum Dis 2007;66:1479-84.

27. Weber U, Hodler J, Kubik RA, Rufibach K, Lambert RG, Kissling RO, et al. Sensitivity and specificity of spinal inflammatory lesions assessed by whole-body magnetic resonance imaging in patients with ankylosing spondylitis or recent-onset inflammatory back pain. Arthritis Rheum 2009;61:900-8.

28. Bennett AN, Rehman A, Hensor EM, Marzo-Ortega H, Emery P, McGonagle D. The fatty Romanus lesion: a non-inflammatory spinal MRI lesion specific for axial spondyloarthropathy. Ann Rheum Dis 2010;69:891-4.

29. Pedersen SJ, Wichuk S, Chiowchanwisawakit P, Lambert RG, Maksymowych WP. Tumor necrosis factor inhibitor therapy but not standard therapy is associated with resolution of erosion in the sacroiliac joints of patients with axial spondyloarthritis. Arthritis Res Ther 2014;16:R100.

30. Eno JJ, Boone CR, Bellino MJ, Bishop JA. The prevalence of sacroiliac joint degeneration in asymptomatic adults. J Bone Joint Surg Am 2015;97:932-6.

31. Frost M, Wraae K, Gudex C, Nielsen T, Brixen K, Hagen C, et al. Chronic diseases in elderly men: underreporting and underdiagnosis. Age Ageing 2012;41:177-83.

32. Jacob L, Breuer J, Kostev K. Prevalence of chronic diseases among older patients in German general practices. Ger Med Sci 2016;14:Doc03.

33. Vavricka SR, Schoepfer A, Scharl M, Lakatos PL, Navarini A, Rogler G. Extraintestinal manifestations of inflammatory bowel disease. Inflamm Bowel Dis 2015;21:1982-92.

34. Bernstein CN, Blanchard JF, Rawsthorne P, Yu N. The prevalence of extraintestinal diseases in inflammatory bowel disease: a population-based study. Am J Gastroenterol 2001;96:1116-22.

35. De Kock I, Hindryckx P, De Vos M, Delrue L, Verstraete K, Jans L. Prevalence of CT features of axial spondyloarthritis in patients with Crohn's disease. Acta Radiol 2017;58:593-9. 